\title{
Simulating the Lausanne Peace Negotiations, 1922-1923: Power Asymmetries in Bargaining
}

\author{
Nimet Beriker \\ Bilkent University \\ Daniel Druckman \\ National Research Council \& \\ George Mason University
}

The negotiation leading to the historic Lausanne Peace Treaty provides a setting for exploring the impacts of different power configurations on bargaining behavior. Symmetric and asymmetric coalition structures existed on two key issues in the talks, passage through the straits and the question of civil rights for minorities. A content analysis of the transcripts showed some differences in bargaining behavior between the two power structures. These structures were simulated and compared to a third condition, bilateral negotiations between parties of equal power. Opposing negotiators in the symmetric parties condition were more satisfied with the outcome, achieved faster resolutions, disagreed less, and made fewer competitive statements during the discussions than negotiators from these countries in the coalition conditions. Both similarities and differences were found in the comparison between the processes and outcomes in the actual and simulated negotiations. The results have implications for designing structures that improve negotiations and illustrate some advantages of experimental simulation.

KEYWORDS: negotiating behavior; alternative power structures; experimental simulation; process analysis; perceptions and attitudes; Lausanne peace negotiations.

The historic Lausanne Peace Treaty marked the end of the post-World War I conflicts between allied forces and Turkish nationalists. The treaty was negotiated at a conference held in Lausanne (Switzerland) from November 1922 to July 1923. The parties consisted of the allied powers, the Soviet Union, and Turkey. They negotiated issues in three "baskets": territorial and military questions, the legal status of foreigners, and economic and financial problems. From these baskets, two issues in particular provide an opportunity to test hypotheses about the role of power differences in negotiation.

The discussion of territorial questions highlighted conflicts between Greece and Turkey over passage through the Bosphorus and Dardanelle Straits. 
sat at separate tables. Then Don asked everyone to go to the table representing the session they were least likely to attend! He was teaching us very concretely to open ourselves to truly new ideas.

When his NASAGA board term ran out this fall, Don chose not to run again, but he came anyway to the meeting of the new board, his presence helping us stay centered. "It is time for new people to take up the work," he told us. Yet, the last time I talked with him, just a few weeks before he died, he was considering holding the 1998 conference in Ypsilanti/Ann Arbor20 years after he had first done so (at the University of Louisville in Kentucky).

"My challenge to my colleagues is to take gaming as seriously as we once did," were the last words of Don's Silver Anniversary article. His challenge rings in my heart.

You can reach Don's wife, Valerie, whom he married in 1983, and their sons Adam (11) and Joel (9) at 2907 Baylis Dr., Ann Arbor, MI 48108, USA; telephone 313-971-8158. He is also survived by his mother, Vera Kill, and his sisters, Alia Griffin and Miriam Grut, all of Los Angeles, CA; and his brother, Vern Ifill of New Orleans, LA.

\section{Reference}

Ifill, D. (1994). Taking gaming seriously: Not anymore. Simulation \& Gaming, 25, 211-214.

Barbara Steinwachs lives at the foot of a steep wooded bluff on Keuka Lake in New York's Finger Lakes. The moon rises above the hills across the water from her house, giving night light, since there are no streetlights. She consults with groups for organizational planning and participative learning. She currently chairs the Democratic Party in her tiny rural county and serves as secretary of NASAGA's board.

ADDRESS: risingmoon, Keuka Lake, 1128 East Bluff Drive, Penn Yan, NY 14527, USA; telephone 315-536-7895 voice and fax; E-mail artb@aol.com. 
Positions taken by the Greek negotiators were supported by the allied coalition, whereas those taken by the Turkish delegates were supported by the Soviet representatives. The situation was symmetrical in terms of power; each minor country was aligned with major powers in the discussion. Issues concerning minorities were of less interest to the Soviet delegation, leading to an asymmetric confrontation between the weaker Turkish negotiators and the stronger allied coalition. The two issues provide a contrast between alternative power configurations: symmetric in the case of the straits question and asymmetric on the minorities issue. These differences can be analyzed for impacts on negotiating behavior.

\section{(A)Symmetry in International Negotiation: Some Hypotheses}

Symmetrical and asymmetrical power configurations are important aspects of multilateral diplomacy. Analyses by Hopmann and associates document the impacts of structural asymmetries on the interactions within several negotiations, including the Seabeds Denuclearization Treaty (Hopmann, 1974), the Conference on Security and Cooperation in Europe (Hopmann, 1978), the UN Special Session on Disarmament (King, 1979), and the Mutual and Balanced Force Reductions talks (Hopmann, 1977). These analyses illuminate the prevalence of coercive tactics, in the form of commitments and threats or vetoes and text bracketing, used by the stronger parties to elicit compliance by the weaker delegations. In these cases, the superpowers used their threat potential by acting together to preserve their joint interest in domination over their blocs and the nonaligned states. In contrast to stronger parties, weaker bargainers have been found to exhibit softer negotiating styles (Bacharach \& Lawler, 1981; Husbands, 1977), behave more submissively (Rubin \& Brown, 1975), emphasize their share of the joint gains (Haskel, 1974), attach irrelevant demands or riders to their negotiating positions (Druckman, 1986; Haskel, 1974), and be less effective in encouraging their stronger opponents to reciprocate concessions (Michener, Fleishman, Vaske, $\&$ Statza, 1975) or conciliatory gestures (Tedeschi \& Bonoma, 1977). Asymmetrical power relations result in asymmetrical strategies, styles, and moves leading often to outcomes that favor the stronger more than the weaker party. These findings support the observation of Stern, Bagozzi, and Dholakia (1977) that diplomacy "would probably function better in situations where there are mutual dependence and symmetric power relationships" (p. 370). Symmetry is a condition for compromise outcomes insofar as the parties reciprocate each other's concessions. Komorita and Barnes (1969) found that 
pairs with equal power reached agreement more often, required fewer trials to do so, and made larger concessions than those with unequal power. ${ }^{1}$ Symmetry may, however, lead also to stalemate as each side is reluctant to offer any concessions. This is especially likely when the parties share competitive intentions as shown by the results of experiments reviewed by Rubin and Brown (1975, pp. 244-247).

The studies suggest the hypothesis that equal or symmetrical power among negotiating parties is likely to result in more cooperative choices and better outcomes than unequal or asymmetrical power among the parties. The research to date also indicates that it makes a difference which side of the asymmetry a party is on. Negotiators face a "toughness dilemma," which is described by Zartman (1991):

The tougher a negotiator, the greater her chance of getting an agreement close to her position, but the less her chance of getting an agreement at all, whereas the weaker a negotiator, the greater his chance of getting an agreement, but the less his chance of getting that agreement close to his position. (p. 68)

This is a fundamental dilemma of negotiating behavior related to the power positions of the parties. For the stronger party, the choice is between a favorable agreement or stalemate. For the weaker party, the choice is between an unfavorable agreement or stalemate. At issue is how a weaker party can improve its outcomes in negotiation. This study is designed to address this issue.

The trend toward multilateralism in international diplomacy presents opportunities for weaker states to improve their outcomes. They can "equalize" the power balance by aligning with stronger partners in negotiation. Multilateralism can, however, also work to their disadvantage if, for example, they are isolated and must confront stronger opponents. The Lausanne talks illustrate these two power configurations, both of which are commonly found in multilateral negotiations, namely, weak nations aligned with stronger partners in opposition to a similarly configured coalition and alone in opposition to stronger nations. Based on the earlier results, reviewed above, the symmetrical configuration would be expected to produce more satisfactory outcomes than the asymmetrical structure. The reciprocity needed to obtain agreements is more likely to occur between equal-power opponents. The contrasting structures, symmetrical and asymmetrical coalitions, can be compared in analyses of the actual negotiation transcripts and in a simulation of the conference.

It may also be the case, however, that the intracoalition bargaining needed to develop positions may pose problems for the intercoalition negotiations. Analyses by Hopmann $(1974,1978)$ and by King $(1976,1979)$ showed that the intra-alliance bargaining can delay the interalliance talks as well as increase 
the competitive posturing of parties in both (or all) the alliances. Parties within each alliance must reconcile their differences in order to present a common position in the negotiations. One result of this process is enhanced alliance cohesion, which has been shown to increase threat perceptions, leading to further cohesion and competitive posturing in the interalliance talks. (For discussions of the relationship between alliance cohesion and threat perception, see Holsti, Hopmann, \& Sullivan, 1973; Ward, 1982; and Druckman \& Hopmann, 1991.) Thus bargaining between symmetrical coalitions may be less effective than bargaining between single parties.

With regard to the weaker parties in a coalition, the research suggests that they have limited influence over the positions adopted by the more powerful members. Their concerns about possible condominium relationships between powerful members of the opposing coalitions may cause them to be competitive in the intercoalition talks (Druckman \& Hopmann, 1991; Hopmann, 1977). In addition to the cohesion pressures noted above, membership in a coalition may serve to bolster their confidence in defending their positions. These factors are likely to cause weak parties to be more competitive in coalition talks than when they negotiate alone with other single parties.

Weak parties may be able to improve their outcomes by negotiating with other weak parties in bilateral conferences. Komorita and Barnes (1969) found that negotiators in the low equal-power condition were more effective overall than those in the high equal-power condition. Other experiments showed that the smaller the total amount of power in the negotiating system, the more effective the negotiations. Of the 17 studies reviewed by Rubin and Brown (1975), 11 found that low equal-power pairs negotiated more effectively than high equal-power pairs.

Recent comparative case analyses showed that conference size was an important influence on process and outcomes. Bilateral conferences between weak nations produced more efficient processes and stable, binding outcomes than the multilateral conferences in which those nations were involved (Druckman, in press). Outcomes may benefit the strong coalition partners more than the weak parties in multilateral negotiations; the weak parties risk being exploited by their stronger partners. Further clarification for these hypothesized effects is provided by this study.

These studies suggest another hypothesis. This is that negotiations between weak parties of equal or symmetrical power are likely to result in more cooperative interactions and better outcomes than negotiations between coalitions of equal or symmetrical power.

Taken together, the hypotheses suggest that symmetrical negotiations between weak parties are likely to be more effective than talks between 
coalitions of parties with equal power. The symmetrical coalition structure produces delays and competitive posturing by the parties. The symmetrical talks between coalitions may, however, be more effective than negotiations between unequal-power or asymmetrical parties. The asymmetrical structure works to the disadvantage of the weaker parties, making it harder for them to achieve satisfactory agreements.

This study was designed to test these hypotheses by comparing the effects of alternative structures on negotiating behavior. A simulation was designed to reproduce certain aspects of the Lausanne Peace Conference. The two power configurations represented in the Lausanne talks were created and compared to a third bilateral configuration. This consisted of similar coalitions of strong and weak parties, a weak nation in opposition to a coalition consisting of both strong and weak nations, and a bilateral discussion between two weak parties. Effects were assessed on indexes of the negotiating process, its outcome, and perceptions of the situation. The simulation results were also compared to those obtained from analyses of the transcripts of the actual talks.

The primary analysis is based on an experimental simulation of the negotiations. A second analysis is based on a coding of the transcripts of the actual talks. These analyses are complementary. The two power configurations illustrated by the straits and minorities issues in the actual talks are compared, using content analysis for effects on negotiating rhetoric and tactics. Lacking, however, in this comparison is insight into the causal relations among conditions, process, and outcome. By replicating the case in the laboratory, the analyst can assess statistical relationships among these variables. Control over the way conditions are defined and measurement of perceptions and behaviors lends confidence to interpretations of the findings. Moreover, we are able to create conditions not present in the historical case, namely, symmetrical negotiations between two weak parties. Inevitably, however, the laboratory model is only a simplified version of the actual case - shorter time frame; student role-players; and a less elaborate, or orchestrated, historical context for the negotiations. As such, the findings may be more relevant to negotiations in general than to specific cases (see Mahoney \& Druckman, 1975). We return to these issues in the discussion section below.

The remainder of the article is divided into several sections. The section on method consists of describing the issues and procedures used in the simulation, the experimental conditions, and the system used to code the negotiation transcripts. We turn then to the results obtained from both the simulation and content analysis of the transcripts. Finally, implications of the findings for theory, method, and practice are discussed. 


\section{Method}

This section is divided into three parts: The simulation procedures, the experimental conditions, and the negotiation transcripts.

\section{The Simulation}

The simulation recreated certain aspects of the Lausanne talks and was an adaptation of an exercise used for experimentation by Druckman, Broome, and Korper (1988). Participants - communications students at George Mason University-were asked to take the role of chief of delegation from Turkey, the Soviet Union, Greece, or a coalition of allied powers. The exercise highlighted four issues confronting the working group on the straits. Before presenting the issues, participants were briefed on the historical events leading up to the talks, including a chronological listing of the events and a geographical map, as well as the setting surrounding the negotiations. In this section, we describe the issues, procedures, and postnegotiation questions asked of the participants. (For more details on the simulation, see Beriker, 1992.)

\section{The Issues}

In their role as members of the working group on the straits, participants negotiated four issues: demilitarization of the straits, passage of commercial vessels through the straits, composition of the commission of the straits, and passage to the Black Sea through the straits. Assigned initial positions on each issue paralleled the positions taken by the parties in the actual talks. Alternative positions on each issue were arranged on a continuum with the starting positions of the opposing parties at the ends.

With regard to the size of the demilitarized zone, Greece and the Allies argued that the zone be 15 miles in length on each side of the straits; Turkey and the Soviet Union maintained that Turkey should maintain its sovereign rights of the region and argued for no demilitarized zone. The alternative positions on this issue were aligned as follows:

\begin{tabular}{lccr}
\multicolumn{1}{c}{$A$} & $B$ & $C$ & \multicolumn{1}{c}{$D$} \\
\hline 15 miles & 7 miles & 3 miles & $\begin{array}{r}0 \text { miles } \\
\text { (Allied and } \\
\text { Greek position) }\end{array}$ \\
\hline
\end{tabular}


On the issue of passage through the straits, Greece and the Allies advanced that all merchant ships be allowed free passage during a war (position A on the continuum). In contrast, Turkey and the Soviet Union advocated that the straits be closed to all commercial vessels during wars (position $\mathrm{C}$ ). The compromise position on this issue was that freedom be granted only to neutral vessels (position B). On the third issue, composition of the commission, the extreme starting positions were all members of the League of Nations, including Turkey and the Soviet Union if and when they become members (A) (advanced by Greece and the Allies) versus jurisdiction vested only in the hands of the Turkish government (D). Between these extremes were two compromise positions: All members of the league plus Turkey and the Soviet Union whether or not they become members (B) and all members of the league with Turkey as president of the commission (C).

On the fourth issue, passage of warships through the straits, Greece and the Allies argued in favor of free entry of any tonnage by non-Black Sea powers whereas Turkey and the Soviet Union argued for total closure of the straits to warships. The alternatives were aligned as follows:

$A$

Free entry of
any tonnage
(Allied and
Greek position)

$B$

Each non-Black Sea
country may send
fleets equal to the
most powerful fleet
in the Black Sea

$C$

The total sent by non-
Black Sea countries
will not exceed
the most powerful
fleet in the Black Sea

No entry

(Turkey and Soviet position)

Representatives could discuss the issues in any order allowing for the possibility of trade-offs. At the conclusion of the talks, they were asked to circle the agreed position on each issue, which could include an alternative not on the continuum; they were also to initial any agreements reached. In addition, they were asked to circle the option that reflected their desired outcome and resistance points (how far willing to go) on each issue.

\section{The Procedures}

The exercise was divided into four parts. The first part consisted of orientation and background. Participants were assigned roles, were read the historical material describing events leading up to the negotiation and a chronology of the key events since the end of World War I, and were provided with information about the structure of the parties, which varied by experimental condition as described below. The second part consisted of a 35- 
minute preparation session. Representatives were asked to study the four issues, learn about their opponent's positions and the other alternatives, and develop positions for the negotiation to follow. Coalition partners were encouraged to caucus with each other in order to develop a common strategy. Participants were now ready to negotiate. They were given 45 minutes to discuss the four issues with the aim of reaching an agreement on some or all of them. With their permission, the negotiation was tape recorded for later analysis. In order to obtain a record of moves or concessions, the negotiators were asked to record their position at intervals of 10 minutes. At the conclusion of the negotiation, either upon attaining agreement on the issues or after 45 minutes, representatives were asked to record the agreements and respond

privately to the questions on desired outcome and resistance points as noted above. They were also asked to record the time taken to negotiate the issues. The final part consisted of a postnegotiation questionnaire. Questions were asked about their perception of the power similarities and differences (checks on the manipulated conditions), satisfaction with the outcome, future relationships with the other parties and visions of the way the conflict might develop in the future, perceptions of the situation as win-lose or problemsolving, role identification, and ratings of the opponent and of the communication climate in which the negotiation took place. Participants were then debriefed on the purpose of the simulation and the way the data would be treated for analysis.

\section{The Experimental Conditions}

Three structural configurations were designed for comparison. One consisted of symmetric coalitions, Turkey and the Soviet Union versus Greece and the Allies. Another consisted of an asymmetric configuration, pitting Turkey against a coalition of Greece and the Allies. These were bilateral talks in the context of multilateral structures. The third was a negotiation between the two weak countries, Turkey and Greece. Each configuration is described briefly in turn.

\section{Symmetric Coalitions}

Paralleling the structure of parties discussing the straits issue in Lausanne, each weak nation (Turkey and Greece) had strong partners. The Turkish negotiator was told that he or she represented a militarily weak country in partnership with one of the strongest nations in the world. Emphasizing the importance of national sovereignty, the instructions informed them that the Soviets supported their positions as a way of protecting their interests and 
security in the Black Sea. The aftermath of the war left Greece in a similar weak position, but they were intent on blocking Turkey's interests with the support of allied partners consisting of France, Britain, and Italy. They were also cautioned about the consequences of failing to resolve these issues. The Soviet negotiator was told that he or she represented a strong country whose interests were served best by advancing arguments in favor of Turkish sovereignty over the straits. They were told that they faced a powerful coalition of interests opposed to these positions.

The Greek negotiator was told that he or she represented a militarily weakened nation threatened by the possibility of Turkish control over the straits as well as by the onset of another war with its neighbor. The chance for a favorable settlement on these issues was bolstered by the support of the European allies who view "your country as a potential satellite in the Near East." The representative of the allied nations was told about the strategic advantages of supporting Greece's interests against the possibility of Soviet hegemony in the region. Emphasizing their concern for post-World War I stability, the allied negotiator was encouraged to support positions that would prevent Turkish control of the straits. Like the other negotiating representatives, the allied negotiator was apprised of this "unique opportunity" to achieve a lasting peace in the region.

\section{Asymmetric Configuration}

Paralleling the structure of the parties discussing the minorities issue at Lausanne, this condition pit Turkey against the powerful coalition of Greece and the Allies. The Turkish representative was told that he or she was faced with the prospect of defending its interests in preserving control of the straits against the desires of a coalition of Greece and the allies intent on preventing Turkish control. Representing a weak country, the Turkish negotiator was confronted with the task of persuading the coalition to change its position. For their part, the Greek and allied negotiators were told about their interests in preventing Turkish control of the straits. As in the symmetric condition, the Greek representative was bolstered by the support of the allied nations, forging a powerful coalition to counter Turkish demands. All parties were informed, however, of the importance of achieving an agreement in the interest of long-term regional stability.

\section{Symmetric Parties}

The two weak parties, Greece and Turkey, were on their own, negotiating only with each other. Although this opportunity did not present itself in the 
Lausanne talks, it provides a comparison with coalition bargaining and a plausible scenario for contemporaneous issues of primary concern only to these countries. Both negotiators were informed of their interests on the issues in a manner similar to the other conditions, the main difference being that they would not be supported at the table by other, more powerful allies. The two nations share the fate of deteriorating conditions, coming together to negotiate these issues in order to improve their situation, to resolve a kind of "hurting stalemate." However, they were made aware that these common interests are offset by competing interests concerning control of the straits.

\section{Participants}

Participants were assigned randomly to one of the three conditions and, then, within each condition, to a role as representative of one of the participating nations. Ninety students of both genders, drawn from a larger pool of communications students at George Mason, participated in the simulation. With 10 sessions run in each condition, a total of 40 students participated in the symmetric coalition condition (4 nations in each of the 10 sessions), 30 in the asymmetric condition ( 3 nations in each session), and 20 in the symmetric parties' condition ( 2 nations in each session). The focus of the analyses was on the negotiating behavior of the Turkish and Greek representatives, both of whom were present in each of the three conditions. Of particular interest are comparisons of the effects of these conditions on the weak parties' negotiating behavior.

\section{The Negotiation Transcripts}

The Turkish language transcripts ${ }^{2}$ from the 11 plenary sessions of blocto-bloc negotiations at Lausanne were coded according to the categories of the bargaining process analysis (BPA) system (Walcott \& Hopmann, 1978; Walcott, Hopmann, \& King, 1977; see also Beriker \& Druckman, 1991, for an analysis of the round-by-round moves made by each bloc based on the coded transcripts). For purposes of this analysis we focus on the discussions of two working groups, the group dealing with the conflict over the Bosphorus and Dardanelle Straits and the group considering the question of protecting the civil rights and freedoms of minority groups. The straits issue is an example of negotiations between two coalitions of roughly equal power. The minorities issue illustrates an asymmetric negotiation between the allied coalition and Turkey. The experimental conditions described above reproduced these bilateral talks as they occurred in a multilateral context. 
Focusing on the weaker parties, Greece and Turkey, the analysis compared negotiating behavior on the two issues in terms of indexes of competitiveness. Each statement made by the delegation's representatives was coded in one of several BPA categories reflecting "hard" (commitments, threats) or "soft" (accommodations, promises) rhetoric. The proportion of hard statements relative to all statements made in the hard and soft categories is regarded as a competitive index. The statements were also coded in terms of whether a speaker agrees or disagrees with his or her opponent, forming a disagree index (ratio of disagrees to all statements coded as either agree or disagree). These indexes were aggregated by round (daily discussions), 7 on the straits issue and 17 on the minorities question. Similar coding of the discussions in the simulation enabled us to compare results from the actual and simulated negotiations. (For more details on the coding procedures, see Beriker, 1992.)

\section{Results}

This section is divided into five parts. First, the impact of the manipulated conditions on perceptions are reported. Second, effects of the experimental conditions on several outcome measures are presented followed by effects on some aspects of the negotiating process. Then, we summarize results on a number of perceptual variables, including perceptions of the opponent and the negotiating climate. Finally, the simulation results are compared to those obtained in the actual conference.

\section{Checks on the Experimental Manipulation}

An attempt was made to ascertain whether perceptions of power differences or similarities between the parties corresponded to the experimental conditions. As expected, the representatives from Greece perceived larger power differences between the opposing parties in the asymmetric condition $(M[$ Mean $]=2.6$ on a 7 -step scale) than in both symmetric conditions: for the symmetric coalition condition, $M=3.9(t[18])=2.28, p<.02$, one-tailed) and for the symmetric parties' condition, $M=4.2(t[18])=2.1, p<.025$, one-tailed). Turkish representatives viewed power differences as having more impact on achieving their desired outcome in the asymmetric coalition condition $(M=5.1)$ than in the symmetric parties' condition $(M=3.5 ; t[18])=$ 2.3, $p<.02$, one-tailed).

Both the Greek and Turkish representatives viewed power similarities as having a stronger effect on the outcome in the symmetric coalition condition ( $M=5.2$ and 4.8 , respectively) than in the asymmetric condition $(M=3.4$ 
and 3.4, respectively; $t([18])=2.6, p<.01$, one-tailed and $t([18])=2.4, p<$ .02 , one-tailed). Similarly, significant differences were obtained for the comparison between the symmetric coalition and asymmetric condition in the expected direction for both parties ( $\mathrm{M}=4.9$ vs. 3.4 for the Greek representatives and $M=5.1$ vs. 3.4 for the Turkish negotiators). In addition, with respect to the effect of power similarities on the process, the Greek representatives viewed the symmetric coalition condition as having more impact than the asymmetric condition $(M=5.4$ vs. $3.6 ; t([l 8])=3.2, p<.001$, one-tailed), whereas the Turkish negotiators viewed the symmetric parties' condition as having more impact than the asymmetric condition ( $\mathrm{M}=4.9$ vs. $3.4 ; t([18])=2.2, p<.02$, one-tailed). These findings indicate that the differences among the experimental conditions had the intended impacts on perceptions of the simulation participants.

\section{Negotiation Outcomes}

The conditions did not differ in terms of the number of issues resolved. Most of the dyads in each condition resolved all of the issues prior to the deadline: 6 of 10 in the symmetric coalition condition, 8 of 10 in the asymmetric condition, and 8 of 10 in the symmetric party condition. With regard to resistance points (how far a party is willing to go to get an agreement), the outcomes of negotiators representing Greece exceeded these points more in the symmetric coalition condition $(\mathrm{R}$ [summed ranks] $=19.3)$ than in the asymmetric $(\mathrm{R}=12)$ and symmetric parties' condition $(\mathrm{R}=13.6)$, $\mathrm{H}($ Kruskal-Wallis one-way ANOVA) $=8.2,2 d f, p=.02$. Negotiators representing both Greece and Turkey were more satisfied with the outcomes in the symmetric parties' condition ( $\mathrm{Ms}=2.5$ and 2.3, respectively, on 7-step scales) than in the symmetric coalition ( $\mathrm{Ms}=3$ and 2.8) and asymmetric conditions $(\mathrm{Ms}=3.6$ and 3$), \mathrm{F}(2,54)=4.07, p<.08$. Condition means for several indexes of negotiating behavior and perceptions are shown in Table $\mathbf{1 .}$

\section{Negotiation Process}

Significant differences were obtained among the conditions on the time needed to complete the negotiations. Negotiators in the symmetric parties' conditions took fewer minutes to resolve the issues $(\mathrm{M}=27.5)$ than those in the symmetric coalition $(M=33)$ and asymmetric conditions $(M=35)$. An ANOVA on the transformed times (square root transformation to stabilize the variances) showed a significant difference among the conditions, $F(2,87)=$ $5.7, p<.05$; negotiators in the symmetric parties' conditions reached faster resolutions than those in each of the other conditions $(t=2.24$ and 2.60 for 
TABLE 1: Means by Condition for Negotiation Processes and Perceptions

\begin{tabular}{lccc}
\hline & Asymmetric & Symmetric Coalitions & Symmetric Parties \\
\hline Time to resolution & $35 \mathrm{~min}$ & $33 \mathrm{~min}$ & $27.5 \mathrm{~min}$ \\
Satisfaction with outcome & & 3.0 & \\
$\quad$ Greece & 3.6 & 2.8 & 2.5 \\
$\quad$ Turkey & 3.0 & & 2.3 \\
Disagreements & .074 & .081 & .050 \\
$\quad$ Greece & .075 & .035 & .057 \\
$\quad$ Turkey & .098 & .082 & .096 \\
Competitive statements & .085 & .125 & .063 \\
$\quad$ Greece & 3.68 & 3.45 & \\
$\quad$ Turkey & 3.43 & 3.35 & 2.27 \\
Perceptions of communication climate (aggregated across scales) & 2.25 \\
$\quad$ Greece & & & \\
$\quad$ Turkey & 3.83 & 3.75 & 2.66 \\
Perceptions of opponent (aggregated across scales) & 3.61 & 2.23 \\
$\quad$ Greece & 3.94 & 3.70 & \\
$\quad$ Turkey & & 3.70 & 2.70 \\
Friendly future relations & 3.80 & & 3.00 \\
$\quad$ Greece & 3.40 & \\
$\quad$ Turkey & & & \\
\hline
\end{tabular}

NOTE: Lower means indicate more satisfaction, fewer disagreements or competitive statements, more positive perceptions of the climate and opponent, and friendlier future relations.

the comparison with the symmetric coalition and asymmetric conditions, respectively). Differences were also found among the conditions on the frequency of disagreements (as a proportion of the total number of agree and disagree statements) and competitive statements (as a proportion of the total number of cooperative and competitive statements) made during the course of the discussions. Negotiators representing Greece disagreed more with their opponents in the symmetric coalition and asymmetric conditions $(M s=.081$ and .074) than in the symmetric parties' condition $(M=.050), F(2,27)=4.3$, $p<.02$. The Turkish representatives disagreed more in the asymmetric condition $(\mathrm{M}=.075)$ than in the symmetric coalition condition $(\mathrm{M}=.035)$, $\mathrm{r}(18)=2.22, p<.025$. The mean for the symmetric parties' condition (.057) was between those condition means but did not differ significantly from either. The Turkish representatives also made more competitive statements in the symmetric coalition condition $(M=.125)$ than in the symmetric parties' condition $(M=.063), t(18)=1.33, p<.10$. The mean for the asymmetric condition (.085) fell between those condition means but did not differ significantly from either (see Table 1). 


\section{Perceptions of the Situation and Opponent}

Differences among the conditions were obtained on postnegotiation questions concerning the negotiation climate and the opposing parties. With regard to the climate, negotiators in the symmetric parties' condition had more positive perceptions than those in the asymmetric condition on 5 of the 8 questions: both Greek and Turkish negotiators viewed the climate as significantly (below the .05 level) more open, more cooperative, more rational, more productive, and more tolerant. Negotiators in the symmetric parties' condition also had more positive views of the climate than those in the symmetric coalition condition on most of the questions; differences between the symmetric coalition and asymmetric conditions were not significant.

A similar pattern of differences was obtained for the ratings of the opposing parties. Significant differences (below the .05 level) among the conditions were obtained on 9 of 13 ratings: negotiators in the symmetric parties' conditions viewed the opponent as being more logical, more trusting, more practical, more compromising, more effective, more organized, friendlier, and less agitated than those in the asymmetric condition. Differences were also obtained between the symmetric parties and symmetric coalition conditions on 5 ratings: symmetric parties' condition negotiators saw their opponents as being more trusting, organized, friendlier, easier, and less agitated. (Means by condition across the scales for perceptions of climate and opponent are shown in Table 1.)

Negotiators were also asked about their future relationship with their opponents. The Greek representatives in the symmetric parties' condition regarded their future relationship with Turkey as likely to be friendlier $(M=$ 2.7 on a7-step scale) than those in the asymmetric condition, $M=3.8 ; t(18)=$ $2.24, p<.05$. Greek negotiators in the symmetric parties' condition also viewed their future relationship with Turkey as being friendlier $(M-2.7)$ than those in the symmetric coalition condition $(M=3.7 ; p<.08)$. The Turkish representatives in the symmetric parties' condition regarded their future relationship with Greece as likely to be somewhat friendlier $(M=3.0)$ than those in the symmetric coalition condition, $M=3.7 ; \mathrm{r}(18)=1.35, p<.10$ (see also Table 1).

\section{Real World Versus Simulation Analyses}

The simulation outcomes and process can be compared to those obtained in the actual negotiations. First, with regard to outcomes, there was considerable correspondence in terms of whether or not the deliberations resulted in agreements: compromise agreements were obtained on each of the four 
issues in the actual talks; in the simulation, 6 of 10 dyads resolved all issues ( 9 of 10 resolved 3 of the 4 issues) in the symmetric coalition condition, 8 of 10 resolved all the issues in the asymmetric condition, and 8 of 10 resolved all the issues in the symmetric parties' condition.

With regard to the nature of the agreement, the extent of correspondence varied from issue to issue. High correspondence was obtained for the rules of passage and demilitarization issues: $90 \%$ of the dyads across the three conditions reached the same compromise agreement obtained in the actual talks, namely, freedom with restrictions; $70 \%$ of the simulation dyads agreed on a limited demilitarization comparable to the zone agreed on by the conference delegates. On the strait commission issue, $50 \%$ of the simulation dyads settled on a Turkish president, the outcome reached by the actual delegates. However, only $10 \%$ of the simulation dyads reached the same agreement obtained in the actual talks on the rules of entry issue, namely, each non-Black Sea country may send fleets equal to the most powerful fleet (USSR) in the Black Sea.

With regard to the negotiating process, differences were obtained on the competitive indexes between the two configurations in the actual negotiations. The Turkish delegates were more competitive when they were in a coalition against another equal-power coalition than when they were a single party against a stronger coalition, $F(1,15)=5.2, p<.05$. In the simulation, the Turkish representatives were more competitive when they were in a coalition against another equal-power coalition than when they were a single party against another single party. The Greek delegates were more competitive when they were part of a coalition facing a single party than when they were in a coalition facing another coalition, $F(1,15)=5.3, p<.05$. Similarly, simulated Greek representatives were more competitive in the asymmetric than in the symmetric coalition condition, although the difference was not statistically significant. Differences between the real-world configurations on disagreements were not significant for either the Greek or Turkish delegates. These results are similar to those obtained in the simulation for the Greek representatives but not for the Turkish representatives. Turkish representatives in the asymmetric condition disagreed more than their counterparts in the symmetric coalition condition of the simulation (see Table 1).

\section{Discussion}

The simulation results indicate that the negotiation process is more efficient and cooperative and that perceptions of the opponent are more positive when parties of equal power negotiate with each other than when they 
negotiate as part of a coalition aligned with a more powerful party or are pitted against a coalition of more powerful parties. Although the conditions did not differ in terms of the outcomes, opposing negotiators from Greece and Turkey in the symmetrical parties condition were more satisfied with the outcomes, achieved faster resolutions, disagreed less, and made fewer competitive statements during the discussions than did negotiators from these countries in the other conditions. They also expected their future relationship with the opposing party to be friendlier than did those in the coalition conditions. Negotiators in the symmetric coalition condition did not differ on most indexes from those in the asymmetric condition. These results lend partial support for the hypotheses presented above. The symmetrical bilateral structure proved to be more effective than the coalition and asymmetric structures on process and perceptions but not on outcomes. The symmetriccoalition structure did not produce better processes or outcomes than the asymmetric structure in either the simulation or the actual negotiations. Possible explanations for these results are discussed in this section. We also discuss implications of correspondences between the experimental and case findings and suggest some advantages of designing simulations for use in experimental research.

Of particular interest is the difference between effects obtained on perceptual or attitudinal measures and those obtained on negotiation outcomes. The favorable ratings of the communication climate and of the opponent by negotiators in the symmetrical parties' condition reflected a more cooperative and efficient negotiating process, but not more resolutions, than were obtained in the other conditions. The apparent trust and cooperation engendered by the symmetrical parties' configuration did not translate into more agreements. These findings are similar to those obtained in other small group laboratory interventions. In their review of team-building evaluation studies, Tannenbaum, Beard, and Salas (1992) found that improvements in team members' perceptions or attitudes were shown more consistently than were behavioral or performance changes. Similarly, in their review of educational gaming evaluations, Randel, Morris, Welzel, and Whitehall (1992) concluded that games elicit more interest and positive attitudes than conventional instruction but show only weak effects on performance: there is a discrepancy between learners' impressions and subjective reports and their performance. The improvements found on motivational variables in these studies may be similar to the positive reports of negotiators in the symmetrical parties' condition of this study. Heightened motivation improved the interactive process more than outcomes, whether measured as improved performance, better learning, or more agreements. With regard to negotiation, however, it may bolster the long-term relations among the parties. 
The distinction between agreements and relationships is relevant. Various aspects of the negotiating situation can influence those social-psychological processes (sentiments and understandings) germane to long-term cooperation. These processes are reflected in the interactions between negotiators. They were affected differently by the experimental conditions. The cooperative (competitive) interactions and positive (negative) perceptions of negotiators in the symmetric parties (coalition) condition(s) should contribute to favorable (unfavorable) relations between (among) those parties. The agreements attained by negotiators in the different conditions were arrived at by different paths, either cooperative in the case of the symmetric parties' condition or competitive for the two coalition conditions. Moreover, these may be different types of agreements, the one contributing to an improved relationship between the parties, the other serving primarily to settle the issues on the table. (See the alternative models proposed by Druckman et al., 1988.) They also suggest contrasting orientations to the conflict induced by the party configurations: problem solving versus competitive bargaining. One sequence of effects takes the following form:

Structure of parties $\rightarrow$ orientation toward negotiation $\rightarrow$ perceptions of climate and opponent $\rightarrow$ types of statements made by representatives $\rightarrow$ issues resolved $\rightarrow$ satisfaction with outcomes $\rightarrow$ postnegotiation relations among parties.

This sequence calls attention to linkages among structures, perceptions, processes, and outcomes. It is offered as hypothesized relationships subject to further research.

Differences obtained on the various indexes of negotiating behavior and perceptions were primarily between the symmetrical parties' condition on the one hand and the coalition conditions on the other. Fewer differences were found between the symmetrical and asymmetrical coalition conditions. These results suggest that power symmetry per se may be less important than the configuration of the parties involved in the negotiation. One interpretation turns on the effects of involving major powers in attempts to resolve regional disputes between minor powers. The major powers may have increased the competitiveness of their less powerful coalition partners, in both the actual talks and in the simulation. Indeed, Turkey was more competitive when in a coalition than when acting alone against a coalition in the actual talks. Greece was more competitive in the Lausanne talks when it was part of a coalition facing a weak opponent. Both countries were more competitive when they were part of a simulated coalition than when they were alone, facing each other. An implication of these findings is to limit the involvement of major 
powers in the talks. They may be more helpful as facilitators or conveners of a negotiation between the equal-power regional actors than as participants in the negotiation (e.g., bringing the Greek and Turkish Cypriots to the table rather than being parties to the negotiation of the current conflict). Still to be learned, however, are the ways in which intra-coalition communication processes lead to competitive negotiating postures. For example, as we noted earlier, do these processes produce the changes in alliance cohesion and threat perceptions that lead to competitive negotiations?

Another interpretation turns on the number of parties in a negotiation. Recent analyses have shown that bilateral talks produce more efficient and cooperative processes and more lasting outcomes than multilateral negotiations (Druckman, in press). However, a more definitive interpretation of these findings in terms of number of parties depends on the results of comparisons involving bilateral talks between equally powerful parties as well as talks between parties who are not equal in power. These alternative bilateral configurations should also produce more efficient and cooperative processes than the multilateral or coalitional arrangements. Such comparisons would inform us of the extent to which the type of parties (mix of powerful and weak actors) or number of parties (bilateral vs. multilateral structures) is the more important influence on negotiating behavior. We have only begun to explore the impacts of various party configurations and structures on the process and outcome of international negotiations.

The simulation designed for this experiment was an attempt to capture certain aspects of an important historical event. Such a retrospective gaming exercise allows for checking correspondences between the actual and simulated processes. ${ }^{3}$ When we observe close correspondences, we might conclude that the simulation is an accurate model of the real-world case or that the situation is responded to in similar ways by the professional diplomats and student role-players. The results of the comparisons made in this study were mixed. On outcomes, both the diplomats and the role-players negotiated agreements on the four issues being contested. And, on two of the four issues (rules of passage and demilitarization), most simulation dyads reached a compromise agreement similar to that obtained at Lausanne. Further probes are needed to ascertain why the different outcomes occurred on two of the issues. Overall, however, it would seem that sufficient correspondences were obtained on outcomes to bolster the argument in favor of a valid simulation. ${ }^{4}$

On process, the enhanced competitiveness of the Turkish delegates in a coalition (as opposed to being a single party facing a coalition) was reproduced in the simulation (negotiators in the coalition condition were more competitive than those in the symmetric parties' condition). Similarly, the Greek delegates were more competitive when facing a single party in both 
Lausanne and the simulation. In addition, with regard to disagreements during the talks, the Greek, but not the Turkish, role-players showed similar results. Such similarities of process as these would seem to provide strong evidence for the impact of coalition membership on negotiating behavior. Being a member of a coalition increased the frequency of competitive statements (but not disagreements) made by both the diplomats and roleplaying negotiators. Still to be investigated are the mechanisms or processes responsible for these effects.

This study illustrates another advantage of experimental simulations. In addition to reproducing aspects of the setting being simulated, the designer can create other conditions and assess processes or perceptions not readily observable in the real-world case. By so doing, the experimental results contribute to the growth of theory, augmenting the role played by field research. In this study, we created an experimental condition not present in the actual situation (namely, symmetric parties) and gathered information about perceptions that could not be obtained from the diplomats at Lausanne. As it turned out, these were critical additions: the key differences were those found on perceptions of negotiators in the symmetric parties' condition versus the two coalition conditions. These findings contribute to our knowledge of the relationship between structures and behaviors. They suggest that bilateral talks between the key regional actors may be more conducive to cooperation during the negotiations and with respect to future relations. Building on these results, further investigations would explore other multilateral and bilateral arrangements that impact on negotiating behavior. More practically, the results suggest ways of improving negotiation by creating structures that are conducive to lasting agreements.

\section{Notes}

1. Of the 27 experiments on power symmetry reviewed by Rubin and Brown (1975), 19 provided support for the hypothesis that equal power among negotiators results in more effective negotiations, 5 reported no difference between equal and unequal power conditions, and 3 reported findings in the opposite direction.

2. The proceedings and associated conference documents are available from Ankara University, Faculty of Political Science, Publication No. 291,1969.

3. Three types of simulations are retrospective, contemporaneous, and futuristic. Retrospective simulations are attempts to reproduce historical events as was done with the case of the Lausanne talks in this study. Results may indicate the extent to which the designer has achieved an understanding of those events. Contemporaneous simulations are descriptions of hypothetical situations that represent typical or generic instances of a situation rather than reproducing details of a specific case. Results have implications usually for a class of situations or types of cases. Futuristic simulations are descriptions of possible future events. They are popular tools for 
contingency planning as in the computer-aided generation of alternative "if... then" scenarios used in sensitivity analyses.

4. Alternative explanations for correspondences between real-world and laboratory results are that (a) the participants in both venues respond in a similar way to factors reproduced accurately in the simulation or (b) the negotiators in both venues have similar "theories" about negotiating behavior. Further probes are needed to decide between these explanations. (See Druckman, 1993, for a detailed discussion of this issue.) Similarly, differences can be explained in alternative ways: different types of negotiators respond differently to the same situation or the key aspects of the situation differ in the two settings. Further research is needed to clarify this issue.

\section{References}

Bacharach, S. B., \& Lawler, E. J. (1981). Bargaining: Power, tactics, and outcomes. San Francisco: Jossey-Bass.

Beriker, N. (1992). Negotiating styles of the minor parties in multilateral peace negotiations: Greece and Turkey at the Lausanne Peace Conference, 1922-23. Unpublished doctoral dissertation, George Mason University, Institute for Conflict Analysis and Resolution.

Beriker, N., \& Druckman, D. (1991). Models of responsiveness: The Lausanne peace negotiations (1922-1923). Journal of Social Psychology, 131, 297-300.

Druckman, D. (1986). Stages, turning points, and crises: Negotiating military base rights, Spain and the United States. Journal of Conflict Resolution, 30, 327-360.

Druckman, D. (1993). The situational levers of negotiating flexibility. Journal of Conflict Resolution, 37, 236-276.

Druckman, D. (in press). Dimensions of international negotiations: Structures, processes, and outcomes. Group Decision and Negotiation.

Druckman, D., Broome, B. J., \& Korper, S. H. (1988). Value differences and conflict resolution: Facilitation or delinking? Journal of Conflict Resolution, 32,489-510.

Druckman, D., \& Hopmann, P. T. (1991). Content analysis. In V. A. Kremenyuk (Ed.), International negotiation: Analysis, approaches, issues. San Francisco: Jossey-Bass.

Haskel, B. G. (1974). Disparities, strategies, and opportunity costs: The example of Scandinavian economic market negotiations. International Studies Quarterly, 18, 3-30.

Holsti, O. R., Hopmann, P. T, \& Sullivan, J. D. (1973). Unity and disintegration in international alliances. New York: Wiley.

Hopmann, P. T. (1974). Bargaining in arms control negotiations: The seabeds denuclearization treaty. International Organization, 28, 313-343.

Hopmann, P. T. (1977, March). Bargaining within and between alliances on MBFR: Perceptions and interactions. Paper presented at the International Studies Association, St. Louis.

Hopmann, P. T. (1978). Asymmetrical bargaining in the conference on security and cooperation in Europe. International Organization, 32, 141-177.

Husbands, J. L. (1977, September). The conventional arms transfer talks: Negotiation as proseletization. Paper presented at the American Political Science Association, Washington, D.C.

King, T. D. (1976, February). Role reversal debates in international negotiations: The partial test ban case. Paper presented at the International Studies Association, Toronto.

King, T. D. (1979, September). Bargaining in the United Nations special session on disarmament. Paper presented at the American Political Science Association, Washington, D.C. 
Komorita, S. S., \& Barnes, M. (1969). Effects of pressures to reach agreement in bargaining. Journal of Personality and Social Psychology, 13, 245-252. Mahoney, R., \& Druckman, D.

(1975). Simulation, experimentation, and context: Dimensions of design and inference. Simulation \& Games: An International Journal, 6, 235-270.

Michener, H. A., Fleishman, J. A., Vaske, J. J., \& Statza, G. R. (1975). Minimum resource and pivotal power theories: A competitive test in four-person coalitional situations. Journal of Conflict Resolution, 19, 89-107. Randel, J. M., Morris, B. A., Welzel, C. D., \& Whitehall, B.

V. (1992). The effectiveness of games for educational purposes. Simulation \& Gaming, 23, 261-276. Rubin, J. Z., \& Brown, B. R. (1975). The social psychology of bargaining and negotiation. New

York: Academic Press. Stern, L. W., Bagozzi, R. P., \& Dholakia, R. R. (1977). Mediational mechanisms in interorgani-

zational conflict. In D. Druckman (Ed.), Negotiations: Social-psychological perspectives. Beverly Hills, CA: Sage. Tannenbaum, S. I., Beard, R. L., \& Salas, E. (1992). Team

building and its influence on team

effectiveness: An examination of conceptual and empirical developments. Amsterdam:

Elsevier. Tedeschi, J. T, \& Bonoma, T V. (1977). Measures of last resort: Coercion and aggression in

bargaining. In D. Druckman (Ed.), Negotiations: Social-psychological perspectives. Beverly

Hills, CA: Sage. Walcott, C, \& Hopmann, P. T. (1978). Interaction analysis and bargaining behavior. In R. T

Golembiewski (Ed.), The small group in political science: The last two decades of development. Athens: University of Georgia Press. Walcott, C, Hopmann, P. T, \& King, T. D. (1977). The role of debate in negotiation. In

D. Druckman (Ed.), Negotiations: Social-psychological perspectives. Beverly Hills, CA: Sage. Ward, M. D. (1982). Research gaps in alliance dynamics. Monograph Series in World Affairs.

Denver: University of Denver, Graduate School of International Studies. Zartman, I. W. (1991). The structure of negotiation. In V. A. Kremenyuk (Ed.), International negotiation: Analysis, approaches, issues. San Francisco: Jossey-Bass.

Nimet Beriker is an assistant professor in the Department of International Relations at Bilkent University in Ankara, Turkey. She received a doctorate from the Institute for Conflict Analysis and Resolution at George Mason University in Fairfax, Virginia. Her teaching and research interests are in the areas of international negotiation and mediation, simulation, and content analysis methods. Her recent article, "Mediating Regional Conflicts and Negotiating Flexibility: Peace Efforts in Bosnia-Herzegovina," appears in the November, 1995 issue of The Annals of the American Academy of Political and Social Science.

Daniel Druckman is principal study director at the National Research Council in Washington, D.C. and senior contract professor of conflict management at George Mason University in Fairfax, Virginia. His PhD is in social psychology from Northwestern University. In addition to being an associate editor of this journal, he serves on the editorial board of four journals and is a founding board member of the new journal International Negotiation: A Journal of Theory and Practice to begin publication in 1996. His many publications are in the areas of negotiation and conflict resolution, group processes, nationalism and political stability, nonverbal communication, simulation, and related modeling methodologies. His article, "Nationalism, Patriotism, and Group Loyalty: A Social Psychological Perspective " (appearing in the Mershon Interna- 
tional Studies Review,) was awarded the 1995 Otto Klineberg prize by the Society for the Psychological Study of Social Issues. He also coedited the special issue of The Annals of the American Academy of Political and Social Science, titled "Flexibility in International Negotiation and Mediation."

ADDRESSES: Nimet Beriker, Faculty of Economic, Administrative and Social Sciences, Bilkent University, 06533 Bilkent, Ankara, Turkey. Daniel Druckman, Commission on Behavioral and Social Sciences and Education, National Research Council, 2101 Constitution Avenue, NW, Washington, DC 20418, USA; telephone 202334-2355; fax 202-334-3584; E-mail ddruckma@nas.edu. 